Infirmary is St Mary's Hospital, Manchester which contains the Department of Clinical Genetics (Professor Harris) which can also provide genetic counselling to our patients' families, as and when appropriate, leaving the community and day care for such patients to a District based but not, I hasten to add and emphasise, a DGH based service.

Over the last five and a half years, our experience has suggested that for a variety of reasons this group has peculiar psychological and nursing and social support requirements, many of which will be self-evident. However, we have had some surprises, most notably being the observation that the true Alzheimer type pre-senile dementia patients retain considerable insight into and affective responsiveness to their predicament and immediate environment, despite the fact that they often have considerable difficulty in communicating their awareness of their predicament and their feelings about it to outsiders, due to their profound language disorder. This last finding has encouraged us to try to place these patients in long-term care settings, especially those which are separate from our provision for our long-term ESMI patients.

With the steady closure of the large mental hospitals, however, and especially with the relocation of District based services, our ability to replicate this service within Salford, when the 'acute' services are relocated away from the large mental hospital, remains uncertain as currently there are no guidelines to suggest the exact level of provision required.

Since January 1982 within the catchment population noted above this team has had clinical contact with 43 persons suffering from Alzheimer type pre-senile dementia, 8 suffering from a presumed diagnosis of Pick's Disease and 6 persons suffering from Huntington's Disease. In addition, I have been asked to see a considerable number of patients with other organic brain syndromes arising before the senium, primarily associated with alcohol abuse, vascular brain disorder and post-traumatic and post anoxic brain damage.

The problems for inner city psychiatric services such as ours are particularly acute vis- $\dot{a}$-vis the provision of services for the younger brain damaged and we are attempting, using the Salford Case Register, to estimate service requirements for this particular group.

It would seem, therefore, that the Public Policy Committee of the College require to address themselves to these issues more closely, as such patients will undoubtedly require a range of Local Authority and Health Authority provision, equivalent to that currently provided for the elderly demented, albeit on a very much smaller scale.

I would suggest that each District Health Authority requires to develop its own in-house services for these groups with additional provision for inner-city areas so that both patients and families can have ready access to locally provided resources.

Prestwich Hospital

I. H. STout

Manchester
Psychiatric health care-private and NHS DeAr SIRS

The gremlins removed a crucial line from my letter in response to Professor Brandon (Bulletin, June 1987). It serves me right for quoting SOGAT as an example of closed shops.

The filleted sentence was making the point that if private psychiatric hospitals can achieve desirable levels of service whilst producing the revenue to fuel further development and to satisfy shareholders or Boards of Governors, then surely the NHS could do at least as well, if properly managed.

I entirely support Professor Brandon's aspirations for high quality health care and his statements about the demoralisation and pseudo-democratisation of the NHS.

I do believe he is unduly pessimistic about the benefits of symbiosis between the NHS and the private sector, and prejudice and mistrust merely ensure that isolationism will prevail. The NHS may have had a virtual monopoly on psychiatric care, but none of us has a monopoly on wisdom.

The White House

S. P. MCKeOWN

Carrwood Road

Wilmslow, Chesire

\section{Responsibilities of consultants}

\section{DeAr Sirs}

I welcome the College's endeavours to look at interdisciplinary relationships in the joint meeting with the British Psychological Society reported in the June 1987 Bulletin (11, 210-212). This report states that "the concept of "ultimate responsibility' was shown to be a myth". The General Medical Council, however, in Professional Conduct and Discipline: Fitness to Practise (April 1987) states that "the doctor should retain ultimate responsibility for the management of his patients because only the doctor has received the necessary training to undertake this responsibility". The College guidelines (Bulletin, July 1984, 8, 123-126) state that "the final decision rests with the consultant on matters where the consultant has the final responsibility". It then states that "with patients the medical role is the prime mover for the whole process of treatment and care".

This remains a hazy area which is becoming increasingly important with the setting up of community mental health teams. Surely dialogue is preferable to denial and I hope that the College will continue to face these issues so as to clarify the responsibilities of consultants.

Prestwich Hospital

C. J. SIMPSON

Manchester 